\title{
Nilai Budaya dalam Serat Ajisaka
}

\author{
Cultural Value in Serat Ajisaka
}

\author{
Erlin Kartikasari \\ Fakultas Bahasa dan Sains \\ Universitas Wijaya Kusuma Surabaya \\ Corresponding email: erlinkartikasari@uwks.ac.id
}

Received: 26 November 2020 Accepted: 19 April 2021 Published: 1 June 2021

\begin{abstract}
One of Javanese literature attached to Javanese people is the story of Ajisaka, which was published among the people in verbal and writing. Ajisaka is a Javanese figure whom the Javanese people consider as the originator of Javanese script. One of the recorded of the story of Ajisaka was the Serat Ajisaka written by J. Kats using Javanese script. Serat Ajisaka is one of the stories from a collection of stories in the book entitled Serat Jawi Tanpa Sekar written by J. Kats, a Dutch writer in 1942. This research aims to describe the cultural values in Serat Ajisaka by J. Kats in 1942 using philology studies. This research uses the descriptive method conducted in three stages, the first stage transcribing data, the second stage transliterating Latin script containing Javanese into Indonesian, then analysing the cultural value in Serat Ajisaka. Serat Ajisaka has several concepts of cultural values, namely: 1) educational values, 2) religious values, 3) leadership values, 4) heroism values, 5) courage values, 6) simplicity values, 7) mutual-cooperation values, 8) moral values, and 9) the value of sacrifice for others.

Keywords: cultural value, Serat Ajisaka, filologi
\end{abstract}

Abstrak: Salah satu kesusastraan Jawa yang lekat dengan masyarakat Jawa adalah cerita Ajisaka yang beredar di kalangan masyarakat secara lisan maupun tulisan. Ajisaka merupakan tokoh Jawa yang dianggap masyarakat Jawa awam sebagai cikal bakal penemu aksara Jawa. Salah satu cerita Ajisaka yang dibukukan adalah cerita Serat Ajisaka yang ditulis J. Kats dengan menggunakan aksara Jawa. Serat Ajisaka tersebut merupakan salah satu cerita dari kumpulan cerita pada buku yang berjudul Serat Jawi Tanpa Sekar yang ditulis J. Kats, seorang berkebangsaan Belanda pada tahun 1942. Penelitian ini bertujuan untuk mendeskripsikan nilai-nilai budaya dalam Serat Ajisaka yang ditulis J. Kats tahun 1942 menggunakan kajian filologi. Penelitian ini menggunakan metode deskriptif yang dilakukan dalam tiga tahap: tahap pertama adalah transkripsi data, tahap kedua adalah transliterasi aksara Latin yang berbahasa Jawa ke dalam bahasa Indonesia, tahap ketiga menganalisis nilai-nilai budaya yang terkandung dalam Serat Ajisaka. Serat Ajisaka memiliki beberapa konsep nilai budaya yaitu: 1) nilai pendidikan, 2) nilai religius, 3) nilai kepemimpinan, 4) nilai kepahlawanan, 5) nilai keberanian, 6) nilai kesederhanaan, 7) nilai gotong royong, 8) nilai moral, dan 9) nilai berkorban untuk orang lain.

Kata kunci: nilai budaya, Serat Ajisaka, filologi

To cite this article:

Kartikasari, E. (2021). Nilai Budaya dalam Serat Ajisaka. Diglosia: Jurnal Kajian Bahasa, Sastra, dan Pengajarannya, 4(2), 177-188. https://doi.org/10.30872/diglosia.v4i2.139 


\section{A. PENDAHULUAN}

Salah satu upaya memperkaya khazanah kesusastraan di Indonesia dilakukan dengan cara menampilkan kembali karya dari khazanah kesusastraan daerah. Sastra atau kesusastraan merupakan ekspresi pikiran dan perasaan manusia, baik lisan maupun tulis (cetakan), dengan menggunakan bahasa yang indah menurut konteksnya. Kehadiran sastra ditengah-tengah masyarakat adalah untuk meningkatkan harkat dan martabat manusia sebagai makhluk berbudaya, berpikir, dan berketuhanan

Karya sastra yang cenderung memantulkan keadaan masyarakat, mau tidak mau pasti akan menjadi saksi zaman. Karya sastra merupakan alat komunikasi kelompok dan juga individu. Karya sastra sekaligus merupakan alat komunikasi yang jitu. Karya sastra merupakan alat komunikasi antara pengarang dengan pembacanya. Pengarang adalah seorang zender (pengirim pesan) yang akan menyampaikan pesan lewat teks kepada ontvanger (penerima pesan).

Adapun alasan cerita Serat Ajisaka ini dipilih karena cerita ini telah lama ditulis oleh J. Kats, yakni tepatnya pada tahun 1942 dengan menggunakan aksara Jawa. Untuk kepentingan analisis, aksara-aksara Jawa tersebut selanjutnya ditranskripsikan ke dalam aksara Latin, dari aksara Latin dapat diketahui bahwa ternyata semua tulisan dengan menggunakan bahasa Jawa, dan berikut diterjemahkan lagi ke dalam bahasa Indonesia. Serat Ajisaka merupakan salah satu cerita dari kumpulan cerita pada buku yang berjudul Serat Jawi Tanpa Sekar. Dengan berlandaskan isi cerita Serat Ajisaka, dapatlah diketahui bagaimanakah keadaan masyarakat pada zaman tersebut. Perlu diketahui pula bahwa Ajisaka merupakan tokoh penting dalam sejarah bahasa Jawa. Sebab dialah orang pertama yang menciptakan aksara/huruf Jawa (dentawyanjana) itu sendiri, Oleh karena itu dianggap krusial untuk menampilkan Serat Ajisaka dalam kajian filologi ini.

Nilai sebagai sistem nilai memiliki keterkaitan yang saling menguatkan dan tidak dapat dipisahkan, yang bersumber dari agama maupun dari budaya dan tradisi humanistik. Nilai menjadikan manusia terdorong untuk melakukan tindakan agar harapan itu terwujud dalam kehidupannya (Winarno, 2011, p. 128). Sedangkan Theodore menyatakan bahwa nilai merupakan suatu yang abstrak, dijadikan pedoman serta prinsip-prinsip umum dalam bertindak dan bertingkah laku (Sabarani, 2012, p. 179).

Salah satu bagian adat yang paling tinggi dan paling abstrak adalah nilai budaya (Supratno, 2010, p. 52). Sistem nilai budaya merupakan konsep-konsep mengenai apa yang hidup dalam alam pikiran sebagian besar masyarakat mengenai apa yang mereka anggap bernilai, berharga, dan penting dalam hidupnya sehingga dapat berfungsi sebagai suatu pedoman yang dapat memberikan arah orientasi kepada kehidupan para warga masyarakat.

Konsep nilai budaya adalah (1) nilai pendidikan, (2) nilai religius, (3) nilai kepemimpinan, 4) nilai kepahlawanan, (5) nilai keberanian, (6) nilai kesederhanaan, (7) nilai gotong royong, (8) nilai moral, dan (9) nilai berkorban untuk orang lain (Supratno, 2010, p. 370). Konsep pendidikan dapat berarti proses pengubahan sikap dan tingkah laku seseorang atau kelompok orang dalam rangka untuk mendewasakan manusia melalui upaya pengajaran, pelatihan, proses, dan pembuatan. Konsep religius dapat berarti bersifat religi, bersifat keagamaan yang bersangkut paut dengan religi. Konsep kepemimpinan dapat berarti perihal memimpin atau cara memimpin. Konsep kepahlawanan dapat berarti orang yang 
menonjol karena keberanian dan pengorbanannya dalam membela kebenaran, pejuang yang gagah berani. Konsep keberanian berarti keadaan atau sifat-sifat berani, konsep keberanian berasal dari konsep berani, yang berarti mempunyai hati yang mantap dan rasa percaya diri yang besar dalam menghadapi bahaya, kesulitan serta menegakkan kebenaran dan keadilan. Konsep kesederhanaan dapat berarti keadaan atau sifat sederhana, bersahaja, tidak berlebih-lebihan. Konsep gotongroyong merupakan suatu konsep yang sangat erat hubungannya dengan kehidupan masyarakat Indonesia, yaitu sebagai masyarakat petani; konsep gotong royong secara singkat dapat berarti suatu sistem kerja sama. Konsep moral dapat berarti suatu ajaran tentang baik buruk yang diterima umum mengenai perbuatan, sikap, kewajiban, akhlak, budi pekerti, susila. Konsep berkorban dapat berarti menjadi kurban, menderita, menyatakan kebaktian atau kesetiaan.

Koentjaraningrat (1990) menyatakan bahwa nilai budaya terdiri atas konsepsikonsepsi yang hidup dalam alam pikiran sebahagian besar warga masyarakat mengenai hal-hal yang mereka anggap amat mulia. Sistem nilai yang ada dalam suatu masyarakat dijadikan orientasi dan rujukan dalam bertindak. Oleh karena itu, nilai budaya yang dimiliki seseorang mempengaruhinya dalam menentukan alternatif, cara-cara, alat-alat, dan tujuan-tujuan pembuatan yang tersedia. Sejalan dengan pandangan Koentjaraningrat tersebut, Sabarani (2012, p. 178) menyatakan nilai dan norma budaya merupakan konsepsi yang ada dalam alam pikiran sebagian besar komunitas tentang kebudayaan yang mereka anggap baik dan buruk. Nilai dan norma budaya bukan konsepsi pribadi, melainkan konsepsi warga komunitas; ada sistem bersama (shared system) komunitas untuk menentukan nilai dan norma pada suatu tradisi.

Berdasarkan pendapat dari para ahli maka konsep nilai budaya yang akan dideskripsikan dalam penelitian ini adalah konsep nilai budaya adalah (1) nilai pendidikan, (2) nilai religius, (3) nilai kepemimpinan, (4) nilai kepahlawanan, (5) nilai keberanian, (6) nilai kesederhanaan, (7) nilai gotong royong, (8) nilai moral, dan (9) nilai berkorban untuk orang lain yang ada dalam Serat Ajisaka yang ditulis J. Kats tahun 1942.

\section{B. METODE}

Jenis penelitian yang digunakan dalam penelitian sastra ini adalah jenis penelitian kuantitatif dengan metode deskriptif sesuai dengan Endraswara (2004), Maeryani (2008), Sudikan (1993), dan Sudikan (2001). Jenis penelitian tersebut dipilih dengan didasari fakta adanya nilai-nilai budaya yang terkandung dalam Serat Ajisaka yang ditulis J. Kats pada tahun 1942. Penelitian ini merupakan bentuk penelitian desk study. Serat Ajisaka ini ada di dalam buku Serat Jawi Tanpa Sekar, jilidan pertama, cetakan ke-7, diterbitkan di Batavia oleh Penerbit Visser \& Co. ditulis oleh J. Kats, seseorang berkebangsaan Belanda pada tahun 1942. Serat Ajisaka terdiri atas 17 halaman yang ditulis menggunakan aksara Jawa cetak, dapat dibaca dengan jelas. Data berupa data kebahasaan. Data dalam penelitian ini dianalisis menggunakan pendekatan kualitatif dengan metode deskriptif, data yang berupa

tulisan aksara Jawa ditranskripsi ke dalam aksara Latin kemudian ditransliterasi ke dalam bahasa Indonesia setelah itu dianalisis menggunakan kajian filologi. 


\section{PEMBAHASAN}

1. Nilai Pendidikan

Konsep pendidikan dapat diartikan proses pengubahan sikap dan tingkah laku seseorang atau kelompok orang dalam rangka untuk mendewasakan manusia melalui upaya pengajaran, pelatihan, proses, dan pembuatan. Sedangkan yang dimaksud dengan nilai pendidikan dalam makalah ini adalah sesuatu yang baik dan benar yang terdapat dalam Serat Ajisaka.

Dalam Serat Ajisaka terdapat berbagai nilai pendidikan antara lain pentingnya mencari ilmu, kesadaran bahwa tanpa belajar menjadikan seseorang itu bodoh, orang pandai itu tempat bertanya, semua ilmu seharusnya dipelajari tanpa harus menganggap salah satunya yang terpenting dan meremehkan ilmu lainnya. Perhatikan penggalan-penggalan cerita berikut.

... Wong pirang-pirang nagara padha anggeguru, amung kari wong nagara ing Mendhangkamolan bae, sing kawruhe isih bingung. Yen ta Brahmana iku anaa ing kene, aku sumeja anggeguru." Ajisaka gumujeng amangsuli "Dora ingkang awartos punika, angindhakaken ing kayaktosanipun. Wondene ingkang kawartos punika inggih kula" (SA, 4-9).

\section{Terjemahan:}

... Banyak orang dari berbagai Negara datang berguru kepadanya, hanya tinggal orang-orang di Negara Mendangkamolan saja yang tidak berguru padanya, sehingga ilmu pengetahuannya masih kurang. Seandainya Brahmana itu berada di sini, saya akan berguru padanya. Ajisaka menjawab sambil tertawa, "Bohong, yang diceritakan orang itu, tidak sesuai kenyataan. Sebab yang diceritakan itu adalah saya."

Ingkang putra lajeng dipun wulang piyambak, anyakep sakathahing wulang. Ajisaka anglajengaken anggenipun memuruk. Tiyang nagari ing Mendhangkamolan sadaya sami anggeguru, sarta suyud dhateng sang Brahmana Sabrang, anggenipun kados sami angabdi (SA, 14-18).

\section{Terjemahan:}

Putra Nyai Janda juga lantas diajari tersendiri tentang berbagai macam pengetahuan. Ajisaka melanjutkan mengajar. Semua orang di Mendangkamolan bersama-sama berguru padanya, serta patuh kepada sang Brahmana tersebut sebagaimana orang mengabdi.

Isi penggalan-penggalan cerita di atas menunjukkan bahwa ilmu itu harus dituntut atau dicari di manapun, wong pirang-pirang padha anggeguru (banyak orang sedang belajar) ... Tiyang nagari ing Mendhangkamolan sadaya sami anggeguru, tidak seorang yang belajar, tetapi banyak orang. Ini juga membuktikan pentingnya ilmu untuk dipelajari.

\section{Religius}

Konsep religius dapat berarti bersifat religi, bersifat keagamaan yang bersangkut paut dengan religi. Sedangkan nilai religius yang dimaksud dalam makalah ini 
adalah yang ada kaitannya dengan masalah religi yang terdapat dalam Serat Ajisaka. Perhatikan penggalan cerita berikut.

"Yen makaten, Paman, tanpa damel anggen sampeyan anggeguru, yen boten tega ing pejah, aluwung sampun anggegurua, bilih boten kula labuhi pejah, boten mantep andelipun tetiyang Mendhangkamolan, ingkang sampun anggeguru dhateng kula, pejah sepisan, gesang salaminipun. Paman, mugi dipun pitajeng dhateng kula, boten ngantos kalampahan kula pejah ..."(SA, 50-54).

\section{Terjemahan:}

"Kalau demikian, Paman, tiada berguna Paman berguru, kalau tidak siap mati, lebih baik tidak usah berguru saja, bila tidak saya bela hingga mati, tidak akan mantap orang-orang Mendangkamolan yang sudah berguru padaku, mati sekali hidup selamanya. Paman, semoga engkau percaya padaku, tak mungkin terjadi saya sampai mati ...."

Dalam kegiatan beragama diajarkan bahwa ada hidup setelah mati. Keyakinan seperti ini tertanam dalam benak setiap muslim, juga penganut agama Hindu atau Budha. Di dalam Serat Ajisaka tidaklah dijelaskan aliran agama apa yang dianut masyarakat pada waktu itu, dimungkinkan saja Islam belum masuk sehingga dimungkinkan pula keyakinan yang dianut adalah agama Hindu atau Budha. Karena tertanamnya keyakinan ada hidup setelah mati (pejah sepisan gesang selamanya), maka setiap manusia berupaya berbuat kebaikan sebagaimana yang dilakukan Ajisaka.

\section{Kepemimpinan}

Konsep kepemimpinan merupakan perihal memimpin atau cara memimpim. Sedangkan yang dimaksud nilai kepemimpinan dalam makalah ini adalah sesuatu yang baik dan benar, yang dimiliki oleh seorang pemimpin agar dapat memimpin lanak buahnya atau rakyatnya secara baik, adil, arif, dan bijaksana yang terdapat dalam Serat Ajisaka. Perhatikan penggalan cerita berikut.

Kacariyos Ajisaka, sasirnanipun Dewatacengkar, wangsul dhateng nagari ing Mendhangkamolan sabalanipun, lajeng anggentosi jumeneng ratu, ajejuluk Prabu Saka. Tetiyang ing Mendhangkamolan ageng alit sami suyud sadaya, icalmirising manah, awit sampun boten wonten ingkang mangsa tiyang. Nagari ing Mendhangkamolan karta, sarta amanggih karaharjan, mirah sandhang, mirah tedha, tulus samuka wis ingkang dipun tanem. Ajisaka ambegipun adil asih paramarta. Tiyang alit sakeca jenjem manahipun, boten wonten lampah ingkang dursila ingkang angresahi anggenipun sami angulajiwa, mengsah boten wonten purun, akathah bramana saking sabrang angajawi ... (SA, 147-155).

\section{Terjemahan:}

Tersebutlah Ajisaka, semusnahnya Dewatacengkar, dia pulang ke negara di Mendangkamolan bersama para pengikutnya, lalu menggantikan menjadi raja, dengan sebutan Prabu Saka. Semua orang di Mendangkamolan, besar kecil tanpa kecuali taat dan hormat padanya, hilang sudah kekhawatiran hati, sebab sudah tiada lagi yang memakan manusia. Negara di Mendangkamolan sejahtera, serta menemukan kedamaian, murah sandang, 
murah pangan, tumbuh semua yang mereka tanam. Kepemimpinan Ajisaka dilandasi keadilan, kasih sayang, dan kedamaian. Rakyat kecil tenang hatinya, tiada yang berbuat jahat sehingga meresahkan kehidupan masyarakat, tiada yang menciptakan permusuhan, banyak brahmana dari seberang datang ke tanah Jawa ....

Ajisaka diceritakan adil dan penuh kasih sayang dalam memimpin rakyatnya di Mendangkamolan sehingga rakyatnya hidup tenang, sejahtera, tidak merasa khawatir, penuh kedamaian, taat, dan hormat padanya. Keadaan demikian tidak hanya dirasakan oleh rakyat dalam negeri sendiri, tetapi dirasakan pula oleh rakyat dari negeri tetangga. Sehingga dengan demikian banyaklah brahmana dari negeri seberang datang ke tanah Jawa pula.

\section{Kepahlawanan}

Konsep kepahlawanan dapat berarti orang yang menonjol karena keberanian dan pengorbanannya dalam membela kebenaran, pejuang yang gagah berani. Sedangkan yang dimaksud nilai kepahlawanan dalam makalah ini adalah sesuatu yang baik dan benar yang dimiliki oleh seseorang tokoh yang menonjol karena keberaniannya dan pengorbanannya dalam membela kebenaran yang terdapat dalam Serat Ajisaka. Perhatikan penggalan cerita berikut.

"Gusti, sarehning iket kawula anasabi talatah dalem, nagari ing Mendhangkamolan dados melik kawula, ing mangke kawula suwun mulungipun saking asta dalem." Dewatacengkar anyumadosi, nanging Ajisaka angungsed, kedah anampeni sakal. Sang nata dipun bujeng ing sapurugipun. Tetiyang ing Mendhangkamolan sampun sami ambalik, suyud dhateng Ajisaka, sami tumut ambujeng ratunipun. Salajengipun sang nata kapengkok ing seganten Kidul, lajeng anggebyur sagajahipun, sirna ... (SA, 113-119).

\section{Terjemahan:}

"Gusti, karena ikat kepala saya telah menutupi daerah kekuasaan Gusti, maka sekarag negeri di Mendangkamolan menjadi milik saya, dan nanti saya minta saat mulungnya harus dari tangan Gusti." Dewatacengkar menyetujuinya, tetapi Ajisaka menariknya secara cepat, dan harus diterima secara langsung. Sang Prabu terlempar sekenanya. Semua orang di Mendangkamolan sudah kembali bersama-sama, semua memberikan hormat pada Ajisaka, bersama-sama ikut memburu rajanya. Selanjutnya, Sang Prabu ditemukan di Lautan Selatan, lantas tercebur bersama gajah tunggangannya sekalian, dan hilang....

Ajisaka berhasil memusnahkan Prabu Dewatacengkar, si raja kejam pemangsa daging manusia (rakyat). Dengan keberhasilannya memusnahkan si raja kejam tersebut, maka secara otomatis dia menyelamatkan semua nyawa rakyat dari kejamnya Prabu Dewatacengkar pula.

\section{Keberanian}

Konsep keberanian berarti keadaan atau sifat-sifat berani, konsep keberanian berasal dari konsep berani, yang berarti mempunyai hati yang mantap dan rasa 
percaya diri yang besar dalam menghadapi bahaya, kesulitan serta menegakkan kebenaran dan keadilan. Keberanian dapat juga berarti berani untuk melaksanakan kehendak, niat, dan tekadnya. Keberanian menjalankan tugas dan kewajiban, keberanian untuk mencapai cita-cita dan tujuan hidup, dan keberanian untuk mempertahankan dan mengembangkan keyakinan, pandangan, dan filsafat hidup, dan keberanian untuk menegakkan kebenaran. Sedangkan yang dimaksud nilai keberanian dalam makalah ini adalah sesuatu yang baik dan benar yang terdapat dalam Serat Ajisaka, yang mana Ajisaka ini memiliki keberanian menawarkan diri pada Prabu Dewatacengkar agar menjadi santapan lezatnya. Perhatikan penggalan cerita berikut.

Ajisaka lajeng kerid ing ngarsanipun Sang Prabu, nyai randha Tenggeran boten kantun, kalah tansah anangis kemawon. Dewatacengkar anjenger ningali bagusipun Ajisaka. Pangandikanipun, "Apa sira kang kapiadreng dadi dhaharingsun, anjaluk bumi saambane iketira." Ajisaka munjuk, "Inggih kawula, bilih andadosaken parenging karsa dalem" (SA, 91-95)

\section{Terjemahan:}

Ajisaka lantas masuk dihadapkan pada Sang Prabu, Nyai Janda Tenggeran tidak ketinggalan mengikutinya, sambil terus menangis saja. Dewatacengkar tertegun melihat ketampanan Ajisaka. Tanyanya, "Apa kamu yang ingin sekali menjadi makananku, dan meminta bumi seluas ikat kepala." Ajisaka menjawab sambil memberikan hormat, "Ya saya, apabila Gusti berkenan" (SA, 95-99).

Keberanian Ajisaka untuk mempertaruhkan hidup dan matinya di hadapan Prabu Dewatacengkar dapat terlihat dalam penggalan cerita di atas. Dia siap menjadi santapan Prabu Dewatacengkar yang kejam. Semua itu dilakukan demi rakyat Mendangkamolan. Kalau rakyat Mendangkamolan justru berlari dan menghindari dari kejaran para pengawal, sebab rakyat tahu bahwa terpegang pengawal, dapat dipastikan nyawanya akan melayang. Tidak demikian halnya dengan Ajisaka. Dia tidak berlari dari kejaran pengawal, tetapi justru menawarkan diri agar menjadi santapan Raja kejam tersebut.

\section{Kesederhanaan}

Konsep kesederhanaan dapat berarti keadaan atau sifat sederhana, bersahaja, tidak berlebih-lebihan. Sedangkan yang dimaksud nilai kesederhanaan dalam makalah ini adalah sesuatu yang baik dan benar yang dimiliki tokoh cerita Ajisaka yang sederhana, bersahaja, dan tidak berlebih-lebihan. Perhatikan penggalan cerita berikut.

Nyai randha wicanten dhateng Ajisaka "nagara ing kene wis misuwur, yen ana Bramana sekti mandraguna, bagus isih enom, limpad ing ngelmu panitisan, pinangkane saka ing sabrang angajawa, anggawa aksara warna-warna, apadene layang tembang kawi, gawene memuruk. Wong pirang-pirang nagara padha anggeguru, amung kari wong nagara ing Mendhangkamolan bae, sing kawruhe isih bingung. Yen ta Brahmana iku anaa ing kene, aku sumeja anggeguru." Ajisaka 
gumujeng amangsuli "Dora ingkang awartos punika, angindhakaken ng kayaktosanipun. Wondene ingkang kawartos punika inggih kula" (SA, 1-9).

\section{Terjemahan:}

Nyai Janda berkata kepada Ajisaka, "Negara di sini ini telah terkenal, bila ada seorang Brahmana yang sakti mandraguna, bagus rupanya, dan masih muda, pandai berbagai ilmu pengetahuan, asal dia dari tanah seberang, dia membawa bermacam-macam aksara, juga tembang kawi, pekerjaannya mengajar. Banyak orang dari berbagai negara datang berguru kepadanya, hanya tinggal orang-orang di Negara Mendangkamolan saja yang tidak berguru padanya, sehingga ilmu pengetahuannya masih kurang. Seandainya Brahmana itu berada di sini, saya akan berguru padanya. Ajisaka menjawab sambil tertawa, "Bohong, yang diceritakan orang itu, tidak sesuai kenyataan. Sebab yang diceritakan itu adalah saya."

Begitu sederhananya sosok Ajisaka sampai Nyai Janda tidak mengetahui bahwa seorang Brahmana terkenal sakti mandraguna, yang bagus rupanya, dan masih muda, serta pandai berbagai ilmu pengetahuan (menguasai bermacam-macam aksara dan tembang kawi) telah berada di hadapannya. Padahal berita tentang kelebihan atau keunggulannya telah terdengar sampai seluruh negeri Mendangkamolan bahkan negeri tetangga juga. Ini membuktikan bahwa Ajisaka adalah sosok yang sederhana, walaupun ilmunya berlebih dan namanya sudah tersohor, namun penampilannya biasa-biasa saja.

\section{Gotong Royong}

Konsep gotong-royong merupakan suatu konsep yang sangat erat hubungannya dengan kehidupan masyarakat Indonesia, yaitu sebagai masyarakat petani; konsep gotong royong secara singkat dapat berarti suatu sistem kerja sama. Konsep gotong royong juga dapat diartikan bekerja bersama-sama atau tolong-menolong. Sedangkan yang dimaksud nilai gotong-royong dalam makalah ini adalah sesuatu yang baik dan benar yang dimiliki tokoh cerita Ajisaka yaitu mau bekerja sama atau tolong-menolong dalam mengerjakan atau melakukan sesuatu pekerjaan atau tugas. Perhatikan penggalan cerita berikut.

Wondening para priyantun ing Mendhangkamolan, ingkang nama bupati,mantri, sapangandhap, taksih kalulusaken ing kalenggahanipun. Pepatihipun inggih taksih Kyai Tengger.Prabu Jaka anunten miyos sinowan ing para abdi, bupati, mantri, punggawa, sarta pandhita. Nyai randha Tenggeran inggih sowan, Patih Tengger kang wonten ing ngarsa. Sang Prabu angandika dhateng Patih "Bapa, undhangna marang sarupane kawulaningsun, yen muridingsun Si Daduga lan Si Manawi ingsun karsakake dadi tetindhihe kawula ingsun bupati wolung atus ... (SA, 143-150).

\section{Terjemahan:}

Sedangkan para priayi di Mendangkamolan seperti bupati, mantri, sampai ke bawah, masih tetap pada kedudukannya semula. Pepatihnya pun masih Kyai Tengger. Prabu Jaka selanjutnya menjalin hubungan baik dengan para abdi, bupati, mantri, punggawa, serta Pandita. Nyai Janda Tenggeran juga 
menghadap, Patih Tengger yang memimpin di depan. Sang Prabu berkata kepada Patih "Bapa, panggilkan kawulaku, muridku yang bernama Si Daduga dan Si Manawi, mereka berdua saya harapkan menjadi bupati memimpin delapan ratus rakyat ....

Jadi, semusnahnya Prabu Dewatacengakar dari Mendangkamolan, Ajisaka lantas dinobatkan rakyat sebagai penggantinya. Dia lalu menjalin hubungan baik dengan para abdi, bupati, mantri, punggawa, dan Pandita untuk bekerja sama/bergotong royong membangun kejayaan Mendangkamolan kembali.

\section{Moral}

Konsep moral dapat berarti suatu ajaran tentang baik buruk yang diterima umum mengenai perbuatan, sikap, kewajiban, akhlak, budi pekerti, susila. Sedangkan yang dimaksud nilai moral dalam makalah ini adalah sesuatu ajaran yang baik dan benar yang dimiliki tokoh cerita Ajisaka yaitu mengenai masalah perbuatan, sikap, kewajiban, akhlak, budi pekerti, atau susila. Perhatikan penggalan cerita berikut.

Nyai randha kaget, wicantenananipun "Begja temen aku katekan kowe, sarehne aku bodho, muga legaa kowe amuruk. "Wangsulanipun Ajisaka "Yen sampeyan suci amundhut wulang, kula sandika kemawon". Nyai randha lajeng dipun wulang ngelmi panitisan, sarta tembang kawi, sampun sampurna kasagedanipun. Ingkang putra lajeng dipun wulang piyambak, anyakep sakathahing wulang.

Ajisaka anglajengaken anggenipun memuruk (SA, 10-16).

\section{Terjemahan:}

Nyai Janda terkejut, komentarnya, "Beruntung sekali saya kedatangan kamu, sebab saya bodoh, semoga kamu berkenan mengajari”. Ajisaka menjawab, "Apabila Nyai benar-benar ingin belajar, saya siap mengajari. Nyai Janda lantas diajari ilmu pengetahuan serta tembang kawi sampai sempurna kemampuannya. Putra Nyai Janda juga lantas diajari tersendiri tentang berbagai macam pengetahuan.

Ajisaka melanjutkan untuk mengajar.

Di Mendangkamolan, Ajisaka mengajarkan berbagai ilmu pengetahuan kepada seluruh rakyat tanpa terkecuali. Bukan hanya mengajari rakyat dari dalam negeri Mendangkamolan sendiri, melainkan rakyat dari Negeri tetangga pula. Dia amalkan berbagai ilmunya untuk banyak orang tanpa imbalan apa-apa. Ini merupakan bukti bahwa Ajisaka berakhlak mulia dan berbudi pekerti luhur.

\section{Rela Berkorban}

Konsep berkorban dapat berarti menjadi kurban, menderita, menyatakan kebaktian atau kesetiaan. Mau berkorban untuk orang lain artinya mau menjadi korban, mau menderita untuk orang lain karena rasa baktinya atau kesetiaannya. Umumnya seseorang mau berkorban karena memperjuangkan sesuatu, seperti antara lain nusa, bangsa, agama, harta, kekasih, kebaikan, dan kebenaran. Sedangkan yang dimaksud nilai mau berkorban untuk orang lain dalam makalah ini adalah sesuatu yang baik dan benar yang dimiliki tokoh cerita Ajisaka, yaitu sifat mau mengorbankan dirinya sebagai santapan Prabu Dewatacengkar, karena rasa 
bakti dan setianya pada rakyat di Negara Mendangkamolan. Perhatikan penggalan cerita berikut.

... awit dipun bujeng badhe kacepeng dhateng utusanipun sang nata. Sareng Ajisaka sumerep makaten, lajeng matur dhateng Kyai Patih "Paman, kula kemawon sampeyan saosaken dados dhaharipun Sang Prabu. Nanging kula gadhah panyuwun, kaparingan siti Mendhangkamolan, wiyaripun namung saiket kula, samasa sampun tampi, kula lajeng kadhahara". Kyai Patih kaget amirengaken aturipun Ajisaka, wangsulanipun "Engger, kula boten kadugi anguyang sakit anempur pejah, aluwung sampeyan memulangake mawon prayogi, awit ing ngriki taksih kathah tiyang bodho". Ajisaka amangsuli, "Kajengipun, Paman, kula pejah, tekad kula badhe ambelani tetiyang ing Mendhangkamolan, ingkang sampun sami anggeguru dhateng kula" (SA, 35-44)

\section{Terjemahan:}

... sebab dikejar dan akan dirangket oleh utusan sang raja. Setelah Ajisaka mengetahui yang demikian, lantas berkata kepada Kyai Patih, "Paman, saya saja berikan untuk makanan Sang Prabu. Tetapi saya mempunyai permintaan, yakni minta tanah Mendangkamolan, yang luasnya hanya seiket kepala saya, setelah permintaan saya dikabulkan, saya siap disantap raja". Kyai Patih terkejut mendengar perkataan Ajisaka, jawabnya, "Engger, saya tiada habis pikir ibarat ada orang menawar sakit membeli mati, lebih baik kamu mengajar saja, sebab di sini masih banyak orang yang bodoh". Ajisaka menjawab, "Biarlah, Paman, saya rela mati, saya bertekad akan membela orang-orang di Mendangkamolan, yang semuanya sudah bersama-sama berguru padaku."

Ajisaka siap berkorban, siap menderita, dan menyatakan kebaktian serta kesetiaannya untuk rakyat di negeri Mendangkamolan. Demikian ini terungkap dalam kata-katanya sendiri, yakni "Kajengipun, Paman, kula pejah, tekad kula badhe ambelani tetiyang ing Mendhangkamolan" (Biarlah, Paman, saya rela mati, saya bertekad akan membela orang-orang di Mendangkamolan).

\section{PENUTUP}

Berdasarkan uraian di atas, dapatlah dituliskan beberapa simpulan bahwa Serat Ajisaka memiliki beberapa konsep nilai budaya sebagai berikut: Nilai pendidikan yang terdapat dalam Serat Ajisaka antara lain pentingnya mencari ilmu, kesadaran bahwa tanpa belajar menjadikan seseorang itu bodoh, orang pandai itu tempat bertanya, semua ilmu seharusnya dipelajari tanpa harus menganggap salah satunya yang terpenting dan meremehkan ilmu lainnya; Nilai religius yang diajarkan adalah bahwa ada hidup setelah mati; Nilai kepemimpinan yang terdapat dalam cerita adalah sikap adil dan penuh kasih sayang seorang pemimpin pada rakyat; Nilai kepahlawanan terlihat pada keberhasilan Ajisaka dalam memusnahkan Prabu Dewatacengkar, si raja kejam pemangsa daging manusia (rakyat). Dengan keberhasilannya memusnahkan si raja kejam tersebut, maka secara otomatis dia menyelamatkan semua nyawa rakyat dari kejamnya Prabu Dewatacengkar pula; Nilai keberanian terlihat pada keberanian Ajisaka untuk mempertaruhkan hidup dan matinya di hadapan Prabu Dewatacengkar, dia siap menjadi santapan Prabu 
Dewatacengkar yang kejam; Nilai kesederhanaan terasa pada penampilan Ajisaka yang begitu sederhananya sampai tidak diketahuinya oleh Nyai Janda bahwa dia seorang Brahmana terkenal, padahal Nyai Janda sedang berhadapan langsung dengannya. Ini membuktikan bahwa Ajisaka adalah sosok sederhana, walaupun ilmunya berlebih, namanya tersohor, namun penampilannya biasa-biasa saja; Nilai gotong royong terlihat saat Ajisaka dinobatkan rakyat sebagai pengganti Prabu Dewatacengkar, dia lalu menjalin hubungan baik dengan para abdi, bupati, mantri, punggawa, dan Pandita untuk bekerja sama/bergotong royong membangun kejayaan negeri Mendangkamolan kembali; Nilai moral terlihat dari kegiatan Ajisaka di Mendangkamolan yang bersedia mengajarkan berbagai ilmu pengetahuan kepada seluruh rakyat tanpa terkecuali; Nilai berkorban untuk orang lain, Ajisaka siap berkorban, siap menderita, dan menyatakan kebaktian serta kesetiaannya untuk rakyat di negeri Mendangkamolan. Demikian ini terungkap dalam kata-katanya sendiri, yakni "Kajengipun, Paman, kula pejah, tekad kula badhe ambelani tetiyang ing Mendhangkamolan (Biarlah, Paman, saya rela mati, saya bertekad akan membela orang-orang di Mendangkamolan).

Rekomendasi yang disampaikan dari hasil penelitian ini adalah hasil penelitian ini dapat dimanfaatkan oleh pemerintah daerah untuk membuat kebijakan dalam hal pelestarian naskah-naskah Jawa. Selain itu, penelitian ini juga bermanfaat dalam pengajaran bahasa Indonesia dan bahasa daerah (Jawa) di sekolah sebagai upaya pelestarian kearifan lokal.

\section{DAFTAR PUSTAKA}

Budiasa, I. M. (2014). Memahami Nilai-Nilai Budaya Tradisi Dalam Lakon Seni Pertunjukan Bali: Sebagai Wahana Pendidikan Karakter Bangsa. Aksara, 26(2), 157-167. https://doi.org/10.29255/aksara.v26i2.157.157-167

Danandjaja, J. (1984). Folklor Indonesia: Ilmu Gosip, Dongeng, dan Lain-Lain. Jakarta: Grafiti Press.

Endraswara, S. (2004). Metodologi Penelitian Sastra. Yogyakarta: Pustaka Widyatama. Hasanah, H., \& Sukmawan, S. (2021). Berbingkai Kemajemukan Budaya, Bersukma Desakalapatra: Selidik Etnografi atas Tradisi Tengger. Diglosia: Jurnal Kajian Bahasa, Sastra, dan Pengajarannya, 4(1), 79-90. https://doi.org/10.30872/diglosia.v4i1.102

Koentjaraningrat. (1990). Pengantar Ilmu Antropologi. Jakarta: Rineka Cipta.

Maeryani. (2008). Metode Penelitian Kebudayaan. Jakarta: Bumi Aksara.

Sabarani, R. (2012). Kearifan Lokal: Hakikat, Peran, dan Metode Tradisi Lisan. Jakarta: ATL.

Sudikan, S. Y. (1993). Metode Penelitian Sastra Lisan. Surabaya: Citra Wacana. Sudikan, S. Y. (2001). Metode Penelitian Kebudayaan. Surabaya: Citra Wacana.

Supratno, H. (2010). Sosiologi Seni: Wayang Sasak Lakon Dewi Rengganis. Surabaya: Unesa University Press. 
